\title{
Job candidates' reactions to AI-Enabled job application processes
}

\author{
Patrick van Esch $^{1}$ (D) J. Stewart Black ${ }^{2} \cdot$ Denni Arli $^{3}$
}

Received: 22 October 2020 / Accepted: 30 October 2020 / Published online: 19 November 2020

(c) Springer Nature Switzerland AG 2020

\begin{abstract}
Organizations are increasingly using AI-enabled technology and tools in their recruiting processes. However, little is known about how job candidates view AI-enabled job application systems and whether those views influence the likelihood that they will apply for jobs in such cases. Our research finds that attitudes toward AI use in the job application process in general, and attitudes toward organizations that use $\mathrm{AI}$ in the job application process in particular, are strongly related to the intent of prospective employees to apply for jobs at those organizations that have AI-enabled job application processes. Given the growing use of AI technology and tools in candidate recruitment, and given that organizations primarily select from and offer jobs to those who have completed the job application process, a better understanding of what influences candidates' reactions to AI-enabled recruiting could provide valuable insights into how organizations can more effectively manage those activities.
\end{abstract}

Keywords Artificial intelligence (AI) · Job application · Attitudes toward AI $\cdot$ Recruiting

\section{The importance of understanding candidate reactions}

In the last 20 years, the criticality of human capital has grown as intangible rather than tangible assets have increasingly accounted for the majority of firm value $[6,9,40,41$, 58]. This growth in the importance of human capital is largely because people either are the essence of, or are the principal driver of, virtually all intangible assets $[6,7,10$, 40]). This increased importance of human capital has in turn elevated the value of effectively recruiting, selecting, hiring, on boarding, deploying, and retaining people.

From a practical standpoint, before organizations can hire, onboard or optimize performance from their targeted human capital, they first must recruit and select them. Recruiting is primarily concerned with determining the desired candidate pool, attracting candidates, and getting them to apply for open positions [12]. From the pool of candidates who actually apply, selection is primarily concerned with assessing

Patrick van Esch

patrick.van.esch@aut.ac.nz

Auckland University of Technology, Auckland, New Zealand

2 INSEAD, San Francisco, CA, USA

3 Department of Marketing, Labovitz School of Business and Economics, University of Minnesota Duluth, Duluth, MN, USA and choosing those whom the organization would like to hire [28]. The majority of early research on recruiting and selection has focused heavily on the reliability and validity of organizations' selection activities and techniques [80].

As this early stream of research on organizational actions grew, a new line of research emerged in which both the theoretical frameworks and empirical studies focused, not just on organizations' actions, but on candidates' reactions [68]. The majority of this research focused on candidate reactions to selection rather than recruiting. This line of research was seen as important because candidates' reactions to selection were hypothesized to affect a variety of outcomes, including candidate performance on selection assessments (e.g., cognitive tests, work samples, interviews), candidate acceptance of employment offers, and various post-hire work attitudes and behaviors (e.g., job satisfaction, organizational commitment, well-being, resilience, job performance, turnover, see [42] for a meta-analytic review [3].

Despite this heavy focus on candidate reaction to selection, from a practical standpoint, one could make the case that understanding candidate reactions to recruiting was equally, if not more, important. This is because candidate reactions to recruiting directly impact the prerequisite outcome relative to selection-i.e., the decision by candidates to engage in and complete the job application process. After all, a candidate has to apply for a job before the selection process can begin. 
Interestingly, despite recruiting and selection being quite related in practice, the theories that have guided the empirical work on the two topics have been quite different. In the case of candidate reactions to selection, the dominant theoretical frameworks have been founded in organizational justice (e.g., [42]. When you consider that in the case of selection, candidates are on the receiving end of salient organization decisions, it seems quite reasonable that candidates would logically ask if the selection process (i.e., procedural justice) and outcomes (i.e., distributive justice) were fair [42] and for organizational justice to be a central theoretical guide [31]. In the case of recruiting, candidates (not organizations) are the ones making the key choicethey decide whether to apply for a job or not. As a consequence, in the case of recruiting, it is quite reasonable for candidates to be more focused on what would attract them to apply for a job rather than the fairness of the choice or the process. Interestingly, after being selected, candidates are again "back in the decision driver seat" because they decide whether to accept an employment offer or not. This common "choice making" position for candidates of deciding to apply or not and deciding to accept employment or not may explain why attraction and fit theories, not organizational justice theories, have been the dominant guides for both candidate reaction to recruiting research $[78,79]$ and candidate employment choice research $[8,15,55]$.

Attraction and fit theories argue, and the related research has found, that the more attractive the job application process, the job, and the organization, the more likely the candidate is to apply for the job and join the company [46]. However, within this literature, research has focused much more on factors that impact job and organizational attractiveness and the subsequent employment choice and much less on recruiting process attractiveness and the subsequent job application choice. Of the research that has specifically focused on job application choice and candidate reactions that could influence that choice, the more recent studies have examined candidate reactions to web-based recruitment $[16$, $17,88,101,105]$. Given the significant increase in webbased recruiting from 2000 onwards [34], the examination of candidate reactions to this specific technology makes imminent sense.

While web-based or digital recruiting remains relevant today, increasingly recruiting involves artificial intelligence (AI) technology and tools [10]. When we refer to AI technology and tools used in recruiting, we draw on the following definition of AI as "a technology system's ability to correctly interpret external data, to learn from such data, and to use those learnings to achieve specific goals and tasks through flexible adaptation" [52], p. 15). Based on one recent survey, $39 \%$ of companies used AI-enabled tools to a moderate or high degree in recruiting candidates, which was more than double the rate used in selection [70]. Perhaps more importantly, this same survey that found that number of companies that plan to use AI-enabled tools in recruiting over the next two years will double (increasing from 39 to $79 \%$ ). Given the importance of candidate reactions to recruiting, given that few empirical studies have focused on the topic (cf. [93], and given that the use of AI-enabled tools in recruiting is growing, it seems that even a modest study of candidate reactions to AI-enabled recruiting could make worthwhile contributions to both research and practice [94].

\section{Positive candidate reactions to Al-enabled recruiting}

As mentioned, although the use of AI-enabled tools in recruiting is growing, its use is relatively recent [10]. Thus, neither the extant literature on candidate reactions to this specific technology in recruiting (which is sparse) nor the predominant attraction and fit theoretical models offer specific guidance on what would be expected to be the most salient factors for additional study. However, attraction and fit frameworks generally argue that the more attractive aspects of the process are perceived to be, the more likely candidates are to engage in and complete the job application process. Further, attraction can be indirect through signals [27] or direct by the nature of the activity or element within the recruiting process.

\subsection{Indirect attractiveness through the use of AI during recruiting}

Research has demonstrated that candidates can look at what organizations do during the recruiting process not just as objective facts but as a signal of what the organization is like [27]. As a consequence, candidates could perceive the use of AI-enabled technology and tools not just as an objective fact but as a signal as to the nature of the organization. If an organization uses new and leading-edge AI technology in the recruiting process, this may signal that the organization itself is innovative, open, and leading-edge. This general assertion is consistent with research that has examined the relationship between an organization's use of technology other than AI and perceived organizational attractiveness. For example, past research has found that organizations that used social media in general (not necessarily during the recruiting process) were perceived as more attractive by job applicants [37, 56, 73]. More specifically, research has found that organizations that used social media specifically during the recruiting process were perceived as attractive by candidates [57, 65, 94]. In addition, organizations that used digital technology tools in the recruiting process were perceived as attractive by job candidates and these candidates were more likely to engage in and complete the application 
process [47]. These studies suggest that candidates interpret the use of new or leading-edge technologies as positive and attractive signals. As they do, they perceive the organizations as more attractive. The more the organization is attractive in their eyes, the more likely candidates are to engage in and complete the job application process.

In the case of AI-enabled technology and tools in the recruiting process, the use of such tools is relatively recent. Given the general sophistication of such technology and tools, it seems reasonable that many candidates will see such AI-enabled technology and tools as innovative and leadingedge and subsequently as signals that the organization is also innovative and leading-edge. The more candidates hold this perception, the more attractive such organizations are likely to be perceived. The more attractive they are, the more likely candidates would be to engage in and complete associated AI-enabled job application processes. Stated formally:

$\mathbf{H}_{1}$ : Perceived organizational attractiveness, due to the use of AI in the job application process, will positively influence a candidate's intent to engage in and complete that process.

\subsection{Direct attractiveness of Al-enabled technology and tools during recruiting}

As mentioned earlier, in addition to signaling dynamics, engaging with AI-enabled technology and tools during the recruiting process might be directly or inherently attractive. Unfortunately, attraction and fit theories offer little explicit guidance regarding what might be inherently attractive in terms of technology during the recruiting process in general or with AI-enabled technology and tools in particular. However, the research on inherent attractiveness and technology does provide some theoretical guidance [90].

In terms of general inherent attractiveness, scholars have largely referred to this as intrinsic motivation [77]. Intrinsic motivation exists when engaging in an activity by itself is fun, provides a sense of accomplishment, enhances a sense of independence, elevates personal feelings of confidence, and/or increases feelings of being innovative, independent of outcomes that engaging in the activity might produce. The extant literature (which is large) has consistently found that anticipated intrinsic satisfaction is one of the most powerful sources of motivation and attraction to a target. It has also found that the higher the anticipated intrinsic satisfaction, the more likely people are to engage in the activity $[23,67$, $91,97]$. Research specifically examining the use of technology and intrinsic motivation has found that people typically anticipate that using new technology will be intrinsically satisfying [97]. The research has also found that the more users have this perception of a given technology, the more likely they are to engage with and use that technology [21,99].
Participating in a job application process that uses AIenabled tools could be viewed as intrinsically satisfying. For example, using this new and innovative technology might provide a sense of accomplishment, independence, confidence, and feelings of being innovative. To the extent this is the case, we would expect that the stronger the anticipated intrinsic rewards of an AI-enabled job application process, the more likely applicants would be to engage in and complete the job application. Stated formally:

$\mathbf{H}_{2}$ : Anticipated intrinsic rewards, due to the use of AI in the job application process, will positively influence a candidate's intent to engage in and complete that process.

A second and potentially powerful source of direct attractiveness is the novelty of engaging with AI-enabled recruiting tools, though some classify novelty as a particular type of intrinsic motivation [22]. Engaging in novel activities in general can engender a sense of excitement, innovation, and exploration. Research has found that novel activities can be an extremely powerful source of attraction and motivation [13]. Research on the use of technology in particular has found that the more potential users anticipated novelty in the use of the technology, the more likely they were to engage with and use the technology $[10,50,92,100]$. Given the relatively recent application of AI-enabled technology and tools in the recruiting process, it would seem to have potential for being perceived as novel. To the extent that engaging in an AI-enabled job application process is perceived as being novel, it would be attractive and would likely have a positive relationship with job candidates engaging in and completing the job application process. Stated formally:

\section{$\mathbf{H}_{3}$ : Anticipated novelty, due to the use of AI in the job application process, will positively influence a candi- date's intent to engage in and complete that process.}

\section{Negative candidate reactions to Al-enabled recruiting}

The "newness" of AI-enabled recruiting tools, which is at the heart of all three of factors that we hypothesize, could have a positive impact on candidate reactions to and likelihood of engaging with and completing the job application, could also hinder, rather than enhance, use [75]. The newness of a technology could cause individuals to trust it less or to be anxious about using it [68]. 


\subsection{Trust in Al-enabled job application systems}

In their broad review of the literature on applicant reactions to recruiting and selection, [68] note that trust is an "issue which has not yet attracted a great deal of interest in applicant reactions research, but has the potential to be considered an important predictor of applicant reactions." While the applicant reaction literature has not examined trust much, the broader literature has. For example, when citizens have general trust in the political process and believe it is not corrupt, they are more likely to engage in political activities, including voting [96]. Likewise, when employees trust their boss will be fair, they are more likely to speak up, participate in decisions, and offer feedback [35]. Relative to technology, when patients trust that their privacy will be protected in digital medical records, they are more willing to allow medical personnel to access those records [19].

In terms of job candidates' trust in AI-enabled technology relative to recruiting and job applications, because the use is relatively new, there are very limited data available on how much candidates do, or do not, trust AI-enabled job application systems. If we broaden our view beyond recruiting, and examine the literature on the trust of AIenabled tools in general, we find a somewhat mixed picture. For example, Dietvorst et al. [24] found that humans often choose a human forecaster over a statistical algorithm. In contrast, Dijkstra et al. [25] found that participants considering logic problems agreed more with the same argument when it came from an "expert system" than when it came from a "human." Prahl and Van Swol [72] did not find people preferred human advice over automated advice, but they did find that people utilized automated advice significantly less than human advice after the advice was demonstrated to be bad. Logg et al. [61] found that people have higher levels of appreciation for algorithmic recommendations than for recommendations from humans, even when the alternative human recommendations come from experts rather than laypeople. Lastly, Xu et al. [103] found that for low-complexity tasks, consumers considered the problem-solving ability of AI to be greater than that of human customer service agents and were more likely to use AI. However, for high-complexity tasks, consumers viewed human customer service agents as superior and were more likely to use human agents over AI.

Given the newness of the use of AI-enabled tools in recruiting, it seems reasonable to expect that some people may trust the technology, while others may not. Nonetheless the extant literature on trust would suggest that to the extent that candidates trust AI-enabled job application systems, the more likely they are to engage in and complete the associated job application process. Stated formally:
$\mathbf{H}_{4}$ : The greater candidates trust the use of AI in the job application process, the higher will be their intent to engage in and complete that process.

\subsection{Anxiety toward an Al-enabled job application process}

Just as the newness of AI-enabled technology and tools in recruiting can generate novelty, such newness can also engender anxiety. For example, when computers were widely introduced into the workplace several decades ago, such introductions engendered anxiety among workers, even as the technology also promised novelty [89]. Research demonstrated that the greater peoples' anxiety about using a new technology, the lower was their use of that technology [66]. However, the extant literature on job candidate reaction has largely focused on the role of anxiety relative to selection not recruiting. Among the studies that have examined candidate anxiety in selection, the majority has focused on the relationship between candidate test anxiety and related outcomes. Specifically, these studies had found a negative relationship between candidate text anxiety and related outcomes, in particular test performance $[42,68]$. We know of no study that has examined the role of anxiety in candidate reactions to the use of AI-enabled technology and tools in the recruiting process.

Nonetheless, the newness of AI-enabled technology and tools in recruiting could engender anxiety in some candidates toward the technology and tools [51]. To the extent that it does, both theory and past research would assert that candidates' engagement with and completion of process associated with that anxiety-inducing technology would lead them to avoid rather than engage with the process. As a consequence, we would expect that the greater candidates' anxiety about AI-enabled tools in the process, the less willing candidates will be to engage in and complete an AI-enabled job application process. Stated formally:

$\mathbf{H}_{5}$ : Anxiety, due to the use of AI in the job application process, will negatively influence a candidate's intent to engage in and complete that process.

\subsection{The mediating effect of anxiety}

Even though we hypothesize that organizational attractiveness, intrinsic reward, novelty, and greater trust should all have positive relationships with a candidate's intent to engage in and complete the job application process, it is possible that anxiety could mediate each of those relationships. Specifically, anxiety might take up such mental and emotional bandwidth as to leave little room for the other expected positive associations to be expressed. Anxiety would thereby mediate these relationships Fig. 1. Based on 
Fig. 1 Conceptual model

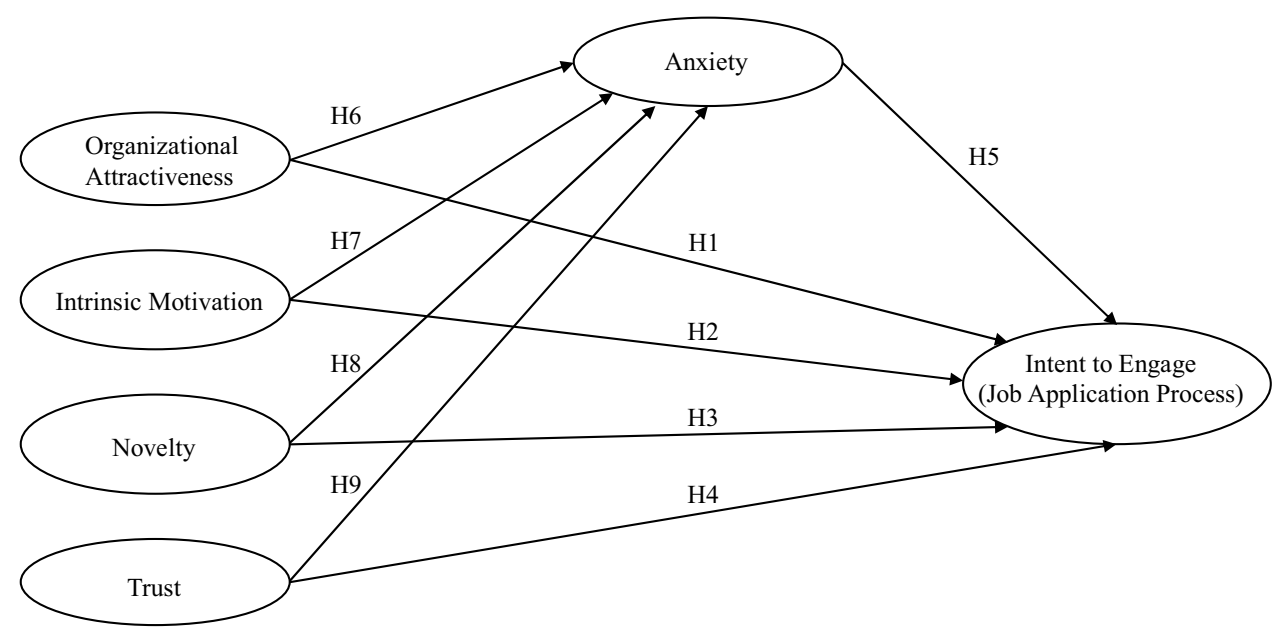

these considerations, we formulated the last hypotheses for this study and stated formally:

$\mathbf{H}_{\mathbf{6}}-\mathbf{H}_{\mathbf{9}}$ : The influence of anxiety, due to the use of AI in the job application process, will mediate the relationship between organizational attractiveness (H6), intrinsic motivation (H7), novelty (H8), and trust (H9) and a candidate's intent to engage in and complete that process.

\section{Method}

In order to examine the relationships between organizational attractiveness, intrinsic motivation, novelty, trust, anxiety and intent to engage in, and complete an AI-enabled job application process, we used a cross-sectional design for this study [59, 62, 83]. Adults $(n=532)$ recruited from an online panel in the USA participated in the study [43, 82]. Participants familiarized themselves with a brief recruiting scenario as the context within which they should give their responses to the various survey items. The scenario specified several key conditions. First, participants were informed that an organization had an open job. Second, the scenario informed participants that they were interested in and attracted to the job, but without specifying what the job was, or why they were attracted to it. Third, participants were informed that the organization with the open job used $\mathrm{AI}$ in its job application process, but without specifying any details of exactly how the company used AI in the process. In addition, the scenario made no mention of any anticipated efficiency or effectiveness benefits of the AI-enabled process. Also, the scenario did not mention the length of time the organization had been using $\mathrm{AI}$ in the recruiting process. In general, the scenario was purposefully brief for two reasons. First, it was brief to avoid shaping participants' perceptions of and attitudes toward an AI-enabled job application process, and thereby allowing participants' existing perceptions and attitudes to remain operational. Second, it was brief because often organizations do not provide any information on their AI-enabled job application systems and typically only mention that they may use $\mathrm{AI}$ in the process. Finally, the scenario also included the definition of artificial intelligence by Kaplan and Haenlein [52] referred to earlier $[4,11,14,18,20,32,33,36,41,45,48,49,54,60,64,69$, $76,81,84-87,95]$.

After reading the job-based scenario, participants were asked a series of questions. The outcome variable was participants' intent to engage in and complete the AI-enabled job application process.

\subsection{Measures}

Adapted scale items were used with wording modifications to focus on the specific issue of an AI-enabled job application. Candidates' Intent to Complete an AI-enabled job application process was measured using a five-item scale ( $\alpha=0.89$; [29], higher score reflects greater intent to complete). Organization Attractiveness was measured with a three-item scale assessing the extent to which candidates perceived an organization as attractive that used AI technology in the job application process $(\alpha=0.90$; [1], higher score reflects greater organization attractiveness). Anticipated Intrinsic Reward was measured with a five-item scale that assessed the degree to which a job candidate believed that using $\mathrm{AI}$ in the job application part of the recruiting process would lead to positive, personal consequences $(\alpha=0.91$; [26], higher score reflects greater intrinsic reward). Novelty was measured with a four-item scale assessing the degree to which a person viewed $\mathrm{AI}$ in the job application part of the recruiting process as being novel and arousing curiosity $(\alpha=0.87$; [38]; higher score reflects greater novelty). Trust was measured with a two-item scale assessing the extent to respondents felt using $\mathrm{AI}$ in the job application part of the 
recruiting process was dependable and trustworthy $(\alpha=0.86$; [30], in its original version, the trust scale has three-items; higher score reflects greater trust). Anxiety was measured with a three-item scale assessing the degree to which a person is uncomfortable using $\mathrm{AI}$ in the job application part of the recruiting process and would avoid using it $(\alpha=0.85$; [102], higher score reflects greater anxiety).

\subsection{Assessments}

Given that the independent and dependent measures were collected at the same time using the same survey method, we checked for common method variance bias using Harmon's one factor test, since the main construct were measured in a single data collection instrument. We tested a single factor model using all of the items of all our latent variables. The factor combined explained less than $50 \%$ of variance. In addition, we compared the $R^{2}$ values of the endogenous constructs before and after adding the marker variable. Generally, if there are significant differences in the $R^{2}$ value of any endogenous construct, this constitutes evidence of substantial common method bias [53, 71]. The differences were below 0.2 (see Table 4). Thus, the results indicated that common method variance did not pose a problem to the data.

Next, we employed structural equation modeling to test the direct effects. The analysis included a two-step approach of structural equation modeling (SEM) to analyze the data and test hypothesis, using AMOS 22 (maximum likelihood estimation; [2]. We tested the model by conducting a confirmatory factor analysis (CFA). This analysis produced a good fit: standardized $\mathrm{RMR}=0.089, \mathrm{CFI}=0.958$, $\mathrm{TLI}=0.950, X^{2}=558.776(211)$. RMSEA $=0.056$.

We then examined the convergent validity of the model. Convergent validity occurs when (a) all factor loads are significantly over 0.50 threshold [32]. Our results ranged from 0.690-0.945; (b) the average variance extracted (AVE) in items by their respective constructs is greater than the variance unexplained (AVE $\ddagger 0.50$ ); and (c) factor composite reliability (CR) is equal to, or greater than 0.60 . The scores in this study ranged from 0.79 (Intrinsic Motivation) to 0.90 (Novelty). Table 1 reports the results of CFAs. The measurement scales show strong convergent validity.

We subsequently examined the discriminant validity of the model. Discriminant validity is achieved when the variance-extracted estimates exceed the squared correlation estimates [39]. Taken together, across Tables 1 and 2, it is clear that the AVEs of all variables are higher than the squared correlations of any pair of variables, which supports the discriminant validity of all measures.

Finally, to test for mediation effects, two separate biascorrected bootstrap analyses with the mediator (i.e. Anxiety) were conducted using a series of multiple regression analyses [74]. A bootstrap test resamples the data to estimate standard errors and to derive a confidence interval with the bootstrapped sampling distribution. A mediating effect is considered significant if the $95 \%$ confidence intervals do not bracket zero [5, 44]. Meaningful mediating effects can occur without a significant direct relationship between independent and dependent variables [104].

\section{Results}

As hypothesized, we found a significant main effect of organizational attractiveness on the intent to complete the job application process (H1: $\beta=0.251, p<0.001)$. Our hypothesis for intrinsic rewards was also supported $(\mathrm{H} 2$ : $\beta=0.422, p<0.001)$. Additionally, we found a significant main effect of novelty on intent to complete the job application process $(\mathrm{H} 3: \beta=0.219, p<0.05)$. However, trust did not have a significant direct effect on intent to complete $(\mathrm{H} 4$ : $\beta=-0.015, p=0.582$ ). As hypothesized, anxiety did have a significant, and negative relationship with intent to complete (H5: $\beta=-0.126, p<0.05$ ) Table 3.

\subsection{Mediating effects of anxiety}

The mediating effects of anxiety were mixed. Anxiety did mediate the relationships between organizational attractiveness and candidates' intent to complete, as well as trust and candidates' intent to complete (H6: 0.001, 0.041 and H9: $-0.154,-0.012)$. However, anxiety did not mediate the relationships between intrinsic reward and candidates' intent to complete, as well as novelty and candidates' intent to complete $(\mathrm{H} 7:-0.012,0.048$ and H8: -0.059 , 0.008 ) Table 3.

\section{Discussion}

Our research makes three modest but worthwhile contributions. First, it spotlights the difference in theoretical frameworks that have largely guided empirical research on candidate reactions to recruiting and selection and why those differences likely exist and may persist. Second, it extends the theoretical guidance on candidate reactions to AI-enabled technology and tools in recruiting by incorporating the broader intrinsic motivation literature and technology use literature. Third, the paper extends the literature on candidate reactions to recruiting by examining specifically candidate reactions to AI-enabled technology and tools in recruiting. In total we believe this makes a worthwhile contribution not just because there is very little research on AI-enabled technology and tools in recruiting (vs. selection) but also because the use of this technology in recruiting is expected to grow significantly in the coming few years. 
Table 1 Confirmatory factor analysis

Factor
Convergent validity factor loading
Reliability

AVE CR

Intent to engage (job application process) [29] ( 1 = Very likely; 7 = Very unlikely)

How likely would you be to contact a company for more information about a job being offered if you knew you had to utilize $\mathrm{AI}$ in the hiring process?

How likely would you be to ask for a job application if you had to utilize AI in the application process?

0.787

$0.60 \quad 0.88$

How likely would you be to complete the job application process if you had to utilize AI in the application process?

How likely is it that you will actually receive a job offer from this company?

How likely would you be to accept the job if it were offered to you after using AI in the application process?

Organization Attractiveness [1] (1= Strongly disagree, $7=$ Strongly agree)

I admire organizations that utilize new technology such as AI

I feel inspired by organizations that utilize new technology such as AI

0.809

0.842

0.690

0.722

0.893

0.816

0.892

Intrinsic Motivation [26] ( $1=$ Strongly disagree, 7 = Strongly agree)

Applying for a job using AI would provide me with personal feelings of worthwhile accomplishment

Applying for a job using AI would provide me with feelings of enjoyment from using the technology

0.799

0.823

Applying for a job using AI would provide me with feelings of independence

0.830

0.780

Applying for a job using AI would allow me to have increased confidence in my skills

There is novelty in using AI platforms to apply for jobs

0.791

0.863

0.719

I feel like I'm exploring new worlds when using AI platforms to apply for jobs

Trust [30], in its original version, scale has three-items) ( $1=$ Not at all; $7=$ Very much $)$

Using AI to apply for a job seems... 'dependable'

Using AI to apply for a job seems.....'trustworthy'

0.755

Anxiety [102] ( $1=$ Not at all, $7=$ Very much $)$

I hesitate to use AI when applying for a job for fear of making a mistake I cannot correct

I feel insecure about my ability to use the AI technology to apply for a Job

0.756

I have avoided AI technology because it can be intimidating

Table 2 Discriminant Validity

\begin{tabular}{lllllll}
\hline & 1 & 2 & 3 & 4 & 5 & 6 \\
\hline $\begin{array}{l}\text { 1. Intent to engage (job applica- } \\
\text { tion process) }\end{array}$ & $\mathbf{0 . 6 0}$ & & & & & \\
2. Organization attractiveness & $0.611^{* *}$ & $\mathbf{0 . 7 0}$ & & & & \\
3. Intrinsic motivation & $0.748^{* *}$ & $0.485^{* *}$ & $\mathbf{0 . 6 6}$ & & & \\
4. Novelty & $0.735^{* *}$ & $0.568^{* *}$ & $0.858^{* *}$ & $\mathbf{0 . 6 3}$ & & \\
5. Trust & $-0.211^{* *}$ & $-0.162^{* *}$ & $-0.103^{*}$ & -0.092 & $\mathbf{0 . 7 3}$ & \\
6. Anxiety & $-0.264^{* *}$ & $-0.217^{* *}$ & $-0.116^{* *}$ & 0.735 & $0.645^{*}$ & $\mathbf{0 . 6 5}$ \\
Mean & 4.68 & 5.35 & 4.15 & 4.48 & 4.32 & 4.02 \\
Std Dev & 1.31 & 1.30 & 1.33 & 1.36 & 1.64 & 1.59 \\
\hline
\end{tabular}

Notes: Values below the diagonal are bivariate correlations between the constructs; bold diagonal elements represent the average variance extracted (AVEs) for the relevant construct; ${ }^{* *} p<0.001 ;{ }^{*} p<0.05$ 
Table 3 Structural model results (direct and mediating effects)

\begin{tabular}{|c|c|c|c|c|}
\hline Hypothesis & Path/relationship & Path coefficient & $p$ value & Results \\
\hline \multicolumn{5}{|l|}{ Direct effect } \\
\hline $\mathrm{H} 1$ & Organization attractiveness intent to engage (job application process) & 0.251 & 0.000 & Supported \\
\hline $\mathrm{H} 2$ & Intrinsic motivation intent to engage (job application process) & 0.422 & 0.000 & Supported \\
\hline $\mathrm{H} 3$ & Novelty Iintent to engage (job application process) & 0.219 & 0.014 & Supported \\
\hline $\mathrm{H} 4$ & Trust intent to engage (job application process) & -0.015 & 0.582 & Not Supported \\
\hline H5 & Anxiety intent to engage (job application process) & -0.126 & 0.010 & Supported \\
\hline Mediating effect & & Lower & Upper & Results \\
\hline H6 & Organization attractiveness anxiety intent to engage (job application process) & 0.001 & 0.041 & Supported \\
\hline $\mathrm{H} 7$ & Intrinsic motivation anxiety intent to engage (job application process) & -0.012 & 0.048 & Not supported \\
\hline $\mathrm{H} 8$ & Novelty anxiety intent to engage (job application process) & -0.059 & 0.008 & Not supported \\
\hline H9 & Trust anxiety intent to engage (job application process) & -0.154 & -0.012 & Supported \\
\hline
\end{tabular}

Note: $R M R=0.089, C F I=0.958, T L I=0.950, X^{2}=558.776(211), R M S E A=0.056$

Note: Zero (0) does not occur within the lower and upper limit of the $95 \%$ confidence interval

Table 4 Test for common method variance

\begin{tabular}{|c|c|c|c|c|c|c|c|c|}
\hline \multicolumn{4}{|c|}{ Standardized regression weights: (CLF) } & \multicolumn{4}{|c|}{ Standardized regression weights: (No CLF) } & \multirow[t]{2}{*}{ Difference } \\
\hline & & & Estimate & & & & Estimate & \\
\hline Org attractiveness & $\leftarrow$ & ATTRA & 0.892 & Org attractiveness & $\leftarrow$ & ATTRA & 0.892 & 0.000 \\
\hline Org attractiveness & $\leftarrow$ & ATTRA & 0.816 & Org attractiveness & $\leftarrow$ & ATTRA & 0.815 & 0.001 \\
\hline Org attractiveness & $\leftarrow$ & ATTRA & 0.894 & Org attractiveness & $\leftarrow$ & ATTRA & 0.893 & 0.001 \\
\hline Job application & $\leftarrow$ & JOB & 0.816 & Job application & $\leftarrow$ & JOB & 0.813 & 0.003 \\
\hline Job application & $\leftarrow$ & JOB & 0.833 & Job application & $\leftarrow$ & JOB & 0.832 & 0.001 \\
\hline Job application & $\leftarrow$ & JOB & 0.852 & Job application & $\leftarrow$ & JOB & 0.852 & 0.000 \\
\hline Job application & $\leftarrow$ & JOB & 0.676 & Job application & $\leftarrow$ & JOB & 0.675 & 0.001 \\
\hline Job application & $\leftarrow$ & JOB & 0.739 & Job application & $\leftarrow$ & JOB & 0.739 & 0.000 \\
\hline Novelty & $\leftarrow$ & NOVEL & 0.798 & Novelty & $\leftarrow$ & NOVEL & 0.798 & 0.000 \\
\hline Novelty & $\leftarrow$ & NOVEL & 0.829 & Novelty & $\leftarrow$ & NOVEL & 0.828 & 0.001 \\
\hline Novelty & $\leftarrow$ & NOVEL & 0.829 & Novelty & $\leftarrow$ & NOVEL & 0.832 & -0.003 \\
\hline Novelty & $\leftarrow$ & NOVEL & 0.739 & Novelty & $\leftarrow$ & NOVEL & 0.736 & 0.003 \\
\hline Intrinsic & $\leftarrow$ & INTRINSIC & 0.831 & Intrinsic & $\leftarrow$ & INTRINSIC & 0.833 & -0.002 \\
\hline Intrinsic & $\leftarrow$ & INTRINSIC & 0.8 & Intrinsic & $\leftarrow$ & INTRINSIC & 0.801 & -0.001 \\
\hline Intrinsic & $\leftarrow$ & INTRINSIC & 0.822 & Intrinsic & $\leftarrow$ & INTRINSIC & 0.822 & 0.000 \\
\hline Intrinsic & $\leftarrow$ & INTRINSIC & 0.828 & Intrinsic & $\leftarrow$ & INTRINSIC & 0.828 & 0.000 \\
\hline Intrinsic & $\leftarrow$ & INTRINSIC & 0.78 & Intrinsic & $\leftarrow$ & INTRINSIC & 0.78 & 0.000 \\
\hline Trust & $\leftarrow$ & TRU & 0.854 & Trust & $\leftarrow$ & TRU & 0.854 & 0.000 \\
\hline Trust & $\leftarrow$ & TRU & 0.757 & Trust & $\leftarrow$ & TRU & 0.757 & 0.000 \\
\hline Anxiety & $\leftarrow$ & ANXIE & 0.81 & Anxiety & $\leftarrow$ & ANXIE & 0.808 & 0.002 \\
\hline Anxiety & $\leftarrow$ & ANXIE & 0.856 & Anxiety & $\leftarrow$ & ANXIE & 0.855 & 0.001 \\
\hline Anxiety & $\leftarrow$ & ANXIE & 0.779 & Anxiety & $\leftarrow$ & ANXIE & 0.757 & 0.022 \\
\hline
\end{tabular}

The results of the study suggest that (a) the more job candidates view as attractive organizations that use $\mathrm{AI}$ in the job application process, (b) the more they anticipate intrinsic rewards from engaging in an AI-enabled process, and (c) the more they feel that the AI-enabled process is novel, the stronger their intention to complete that AI-enabled job application process. However, when accounting for the presence of these other factors, trust did not exert a unique influence. In contrast, the more candidates are anxious about an AI-enabled process, the less they intend to complete such a process. Whether they are anxious or not, the more they anticipate intrinsic rewards and the more they anticipate novelty in the AI-enabled job application process, the more they intend to complete the process. In contrast, the more they are 
anxious about the process, the more that anxiety attenuates the otherwise positive influence of the organization's attractiveness due to its use of $\mathrm{AI}$ in the job application process. The results also found that when candidates do not perceive AI in the job application process as dependable and trustworthy and when they were anxious about the process, their intention to complete an AI-enabled job application process declined. This suggests that mistrust alone of $\mathrm{AI}$ in the recruiting process may not be enough to dissuade candidates from intending to complete the process, but when combined with anxiety about $\mathrm{AI}$ in the process, the combination can tip the scale and cause their intent to decline.

\subsection{Practical implications}

This research offers several implications for organizations. First, the study found a direct and positive relationship between the extent to which candidates perceive organizations as attractive that use AI in the job application process, anticipate intrinsic rewards from such a process, and view that process as novel and their intent to apply for a job through that AI-enabled job process. This may suggest that organizations may want to highlight, rather than hide, the use of AI in their job application process, as long as they have some indication that the majority of their targeted candidates generally have positive perceptions of AI.

However, because anxiety about an AI-enabled job application process negatively affects candidates' intentions to complete the process and greater anxiety mediates the positive impact of organizational attractiveness, organizations may also want to take steps to lower the anxiety and uncertainty that potential candidates may feel toward the AI-enabled process. This practical implication is further bolstered by the fact that in this study, anxiety combined with less trust, caused candidates to significantly lower their intentions to complete an AI-enabled process. To reduce anxiety, organizations may want to highlight that they have taken various steps to ensure that their AI-enabled process treats protected characteristics such as gender, race, ethnicity and age as neutral elements in the processing and initial screening of candidates. Additionally, to lower anxiety, organizations may want to highlight how many individuals have completed their AI-enabled application process. Finally, they may want to highlight that although $\mathrm{AI}$ is used in the job application process, final hiring decisions are made by the hiring managers with input from relevant individuals.

Second, because anxiety does not mediate the relationships between anticipated intrinsic rewards and intent to complete or perceived novelty and intent to complete, organizations may want to highlight the intrinsic reward and novelty elements of their AI-enabled job application process. To do this, organizations may want to describe the AI-enabled process as "interesting," "new," or "novel" and give candidates more independence and control over the timing of their application. Organizations may want to highlight that their job application process includes aspects such as cognitive games in order to spark potential candidates' curiosity.

\subsection{Limitations and research directions}

Our investigation featured a mediation hypothesis with a non-experimental, cross-sectional design with online participants, so it potentially suffered from a lack of internal validity and possible confounding factors. Future studies should enhance the robustness of our findings by employing replications in more controlled settings, using non-online workers as participants, and/or incorporating neuroimaging evidence.

There is little known about how job candidates react to AI-enabled job application systems specifically and to AI-enabled recruiting and selection systems generally. As a consequence, research lags practice. For this reason, we undertook this study to begin to fill in some of these gaps. Specifically, this study focused on examining how job candidates' perceptions of several factors influenced their intent to complete an AI-enabled job application process. This study used a cross-section survey design in part because gaining access to actual job applicants, live jobs, offered by real organizations actually employing $\mathrm{AI}$ in the job application process is challenging. However, future research might improve on this study by creating experimental manipulations of survey respondents in which the issue of $\mathrm{AI}$ is manipulated to see if the factors examined in this study play a different role when AI is, or is not, involved in the job application process. Further, while the respondents in this study had different perceptions of organizations' attractiveness, anticipated intrinsic rewards, perceived novelty, trust and anxiety, relative to the use of $\mathrm{AI}$ in the job application process, these varying attitudes might be a function of different levels of general familiarity, or direct experience with AI-enabled job application systems. Future studies might fruitfully explore this relationship and further test what happens to the strength of the direct effects examined when subjects have a little, or a lot of familiarity and experience with $\mathrm{AI}$ in the job application process. In addition, experience and familiarity (or the lack thereof) might also influence what type of $\mathrm{AI}$, or the functions of AI that respondents have in mind, when applying for a job offered by a company employing $\mathrm{AI}$ in the job application process. This also represents a fruitful area for future investigation. Finally, the definition provided to respondents, taken from [52], p. 15), does state that a "technology system's ability to correctly interpret external data" (italics added for emphasis) and the word "correctly" could nudge respondents' perceptions of or attitude toward AI-enabled recruiting technology and 
tools in a positive direction. To the extent that this word nudged participants' attitudes in a positive direction, the strength of the results might need to be interpreted with some moderation.

Finally, whether these results would be replicated in magnitude in a setting in which real job candidates were responding to an actual job offering by a specific company utilizing an AI system in the job application part of the recruiting process is difficult to know. Obviously gaining access to such a live situation for research purposes is extraordinarily challenging. Constructing an experimental design in which some actual job candidates are presented with a more traditional job application process devoid of AI, and others are presented with a process that uses AI, is an even more robust research design but even more difficult to secure a real company's cooperation. Nonetheless, to the extent that future research could move in this direction, the results would be more relevant to real practice and might more confidently inform AI-enabled job application practices.

\section{Conclusion}

Investment in $\mathrm{AI}$ is estimated to increase from US\$5B in 2015 to about US $\$ 19.1 \mathrm{~B}$ by the end of 2018 , with further predictions of US\$52.2B by 2021 [63]. The potential efficiency and effectiveness benefits of AI in the job application process are likely to attract continued use by companies. Currently research lags practical application; however, the potential sums spent are so large and potential consequences (positive and negative) so great, that more research should be quickly taken up on the topic.

While much of the potential of AI in the recruiting process is yet to be determined, and the drivers and outcomes yet to be understood, the rise in the importance of human capital is almost certainly here to stay. This is largely because of the massive shift in the underlying basis for competition and the role of intangible assets in creating value is unlikely to reverse. Because of this, companies and executives will place a continued strategic priority on the attraction, selection, and retention of people. To the extent that research on AI can help organizations find the right people, get them to apply, screen out the unqualified applicants, and differentiate between the more and less qualified candidates, it will have important implications for the world of practice.

\section{Compliance with ethical standards}

Confilct of interest On behalf of all authors, the corresponding author states that there is no conflict of interest.

\section{References}

1. Aaker, J., Vohs, K.D., Mogilner, C.: Nonprofits are seen as warm and for-profits as competent: Firm stereotypes matter. J. Consum. Res. 37(2), 224-237 (2010)

2. Anderson, J.C., Gerbing, D.W.: Structural equation modeling in practice: A review and recommended two-step approach. Psychol. Bull. 103(3), 411 (1988)

3. Athota, V.S., Budhwar, P., Malik, A.: Influence of personality traits and moral values on employee well-being, resilience and performance: A cross-national study. Appl. Psychol. 69(3), 653-685 (2020)

4. Bandura, A.: Social Learning Theory. Prentice-Hall, Englewood Cliffs, NJ (1977)

5. Barron, R.M., Kenny, D.A.: The moderator-mediator variable distinction in social psychological research: Conceptual, strategic, and statistical considerations. J. Pers. Soc. Psychol. 51(6), 1173-1182 (1986)

6. Becker, B.E., Beatty, R.W., Huselid, M.A.: The differentiated workforce: transforming talent into strategic impact. Harvard Business Press, Boston, MA (2009)

7. Bhattacharya, M., Wright, P.M.: Managing human assets in an uncertain world: applying real options theory to HRM. Int. J. Human Res. Manag. 16(6), 929-948 (2005)

8. Bidwell, M.J., Briscoe, F.S.: The dynamics of inter-organizational careers. Organ. Sci. 21(5), 1034-1053 (2010)

9. Black, S.: Competing for and with Human Capital. Taylor and Francis, Miltion Park, UK (2019)

10. Black, S.J., Van Esch, P.: AI-enabled recruiting: what is it and how should a general manager use it? Bus. Horiz. 63(2), 215-226 (2020)

11. Bogle, S., Sankaranarayanan, S.: Job search system in android environment-application of intelligent agents. Int. J. Inform. Sci. Techn. (IJIST) (2012). https://doi.org/10.5121/ijist .2012 .2301

12. Breaugh, J.A.: Employee recruitment: current knowledge and important areas of future research. Human. Res. Manag. Rev. 18(3), 103-118 (2008)

13. Cerasoli, C.P., Nicklin, J.M., \& Ford, M.T.: Incentives, intrinsic motivation, and performance: A meta-analysis and theoretical reconciliation. In Academy of Management Proceedings (Vol. 2012, No. 1, p. 11993). Briarcliff Manor, NY 10510: Academy of Management (2012)

14. Chan, D., Schmitt, N., DeShon, R.P., Clause, C.S., Delbridge, K.: Reactions to cognitive ability tests: The relationships between race, test performance, face validity perceptions, and test-taking motivation. J. Appl. Psychol. 82, 300-310 (1997)

15. Chapman, D.S., Uggerslev, K.L., Carroll, S.A., Piasentin, K.A., Jones, D.A.: Applicant attraction to organizations and job choice: a meta-analytic review of the correlates of recruiting outcomes. J. Appl. Psychol. 90(5), 928-944 (2005)

16. Cober, R.T., Brown, D.J., Levy, P., Cober, A.B., Keeping, L.M.: Organizational Web Sites: Web site content and style as determinants of organizational attraction. Int. J. Selec. Assessm. 11(2/3), 158-169 (2003)

17. Cober, R.T., Brown, D.J., Keeping, L.M., Levy, P.: Recruitment on the Net: How do organizational web site characteristics influence applicant attraction. J. Manag. 30(5), 623-646 (2004)

18. Conference Board, "C-Suite Challenge 2018," https://www. conference-board.org/publications/publicationdetail.cfm?publi cationid $=7691$

19. Damschroder, L.J., Pritts, J.L., Neblo, M.A., Kalarickal, R.J., Creswell, J.W., Hayward, R.A.: Patients, privacy and trust: patients' willingness to allow researchers to access their medical records. Soc. Sci. Med. 64(1), 223-235 (2007) 
20. Dastin, J.: Amazon scraps secret AI tool that showed bias against women. Business News, 9 October (2018)

21. Davis, F.D., Bagozzi, R.P., Warshaw, P.R.: Extrinsic and intrinsic motivation to use computers in the workplace 1. J. Appl. Soc. Psychol. 22(14), 1111-1132 (1992)

22. Deci, E.L., Ryan, R.M.: Intrinsic motivation and self-determination in human behavior. Plenum Press, New York (1985)

23. Deci, E. L., \& Ryan, R. M.: Optimizing students' motivation in the era of testing and pressure: A self-determination theory perspective. In Building autonomous learners (pp. 9-29). Springer, Singapore (2016)

24. Dietvorst, B.J., Simmons, J.P., Massey, C.: Algorithm aversion: People erroneously avoid algorithms after seeing them err. J. Exp. Psychol. Gen. 144(1), 114-126 (2015)

25. Dijkstra, J.J., Liebrand, W.B., Timminga, E.: Persuasiveness of expert systems. Behaviour Inform. Technol. 17(3), 155-163 (1998)

26. Dong, B., Evans, K.R., Zou, S.: The effects of customer participation in co-created service recovery. J. Acad. Mark. Sci. 36(1), 123-137 (2008)

27. Ehrhart, K.H., Ziegert, J.C.: Why are individuals attracted to organizations? J Manag. 31(6), 901-919 (2005)

28. Farr, J.L., Tippins, N.T.: Handbook on Employee Selection. Routledge, New York (2010)

29. Feldman, D.C., Klaas, B.S.: Internet job hunting: A field study of applicant experiences with on-line recruiting. Human Resource Management: Published in Cooperation with the School of Business Administration, The University of Michigan and in alliance with the Society of Human Resources Management 41(2), 175-192 (2002)

30. Fletcher, G.J., Simpson, J.A., Thomas, G.: The measurement of perceived relationship quality components: A confirmatory factor analytic approach. Pers. Soc. Psychol. Bull. 26(3), 340-354 (2000)

31. Folger, R., Greenberg, J.: Procedural justice: An interpretive analysis of personnel systems. Res. Personnel Human Res. Manag. 3, 141-183 (1985)

32. Fornell, C., \& Larcker, D. F.: Structural equation models with unobservable variables and measurement error: Algebra and statistics (1981)

33. Francis, H., \& Keegan, A.: The ethics of engagement in an age of austerity: A paradox perspective. J. Bus. Ethics. 1-15. (2018)

34. Freeman, R.B.: The labour market in the new information economy. Oxford Rev. Econom. Policy 18(3), 288-305 (2002)

35. Gao, L., Janssen, O., Shi, K.: Leader trust and employee voice: The moderating role of empowering leader behaviors. Leadersh. Quarterly. 22(4), 787-798 (2011)

36. Gatewood, R., Feild, H. S., \& Barrick, M.: Hum. Resour. Sel. Nelson Education (2015)

37. Keegan, A. E., \& Meijerink, J.: Conceptualizing human resource management in the gig economy: Toward a platform ecosystem perspective. J. Manag. Psychol (2019)

38. Guiry, M., Mägi, A.W., Lutz, R.J.: Defining and measuring recreational shopper identity. J. Acad. Mark. Sci. 34(1), 74-83 (2006)

39. Hair, J. F., Black, W. C., Babin, B. J., Anderson, R. E., \& Tatham, R. L.: Multivariate data analysis 6th Edition. Pearson Prentice Hall. New Jersey. Humans: Critique and reformulation. J. Abnormal Psychol. 87, 49-74 (2006)

40. Hand, J.R.: Lev, Baruch, Intangibles: Management, Measurement, and Reporting. Account. Rev. 77(3), 696-698 (2002)

41. Hand, J.R., Lev, B. (eds.): Intangible Assets: Values, Measures, and Risks: Values, Measures, and Risks. OUP, Oxford (2003)

42. Hausknecht, J.P., Day, D.V., Thomas, S.C.: Applicant reactions to selection procedures: An updated model and meta-analysis. Pers. Psychol. 57(3), 639-683 (2004)
43. Hauser, D.J., Schwarz, N.: Attentive Turkers: MTurk participants perform better on online attention checks than do subject pool participants. Behav. Res. Methods 48(1), 400-407 (2016)

44. Hayes, A.F.: Beyond Baron and Kenny: Statistical mediation analysis in the new millennium. Commun. Monogr. 76(4), 408 420 (2009)

45. Hoffman, R.: Using artificial intelligence to set information free. MIT Sloan Manag. Rev. 58(1), 20 (2016)

46. Hoffman, B.J., Woehr, D.J.: A quantitative review of the relationship between person-organization fit and behavioral outcomes. J. Vocat. Behav. 68(3), 389-399 (2006)

47. Holm, A.: Institutional context and e-recruitment practices of Danish organizations. Empl. Relat. 36(4), 432-455 (2014)

48. Ideal. (2017). 8 Recruitment Software Tools That Speed Up Your Day, Retrieved December 11, 2018, from https://ideal.com/recru itment-software-tools/

49. Ideal. (2018). AI for recruiting: A definitive guide for HR professionals, Retrieved December 6, 2018 from https://ideal.com/ ai-recruiting/

50. Jeno, L.M., Vandvik, V., Eliassen, S., Grytnes, J.-A.: Testing the novelty effect of an m-learning tool on internalization and achievement: A Self-Determination Theory approach. Comput. Educ. 128, 398-413 (2019)

51. Kaplan, A., Haenlein, M.: Rulers of the world, unite! The challenges and opportunities of artificial intelligence. Bus. Horiz. 63(1), 37-50 (2020)

52. Kaplan, A., Haenlein, M.: Siri, Siri, in my hand: Who's the fairest in the land? On the interpretations, illustrations, and implications of artificial intelligence. Bus. Horiz. 62(1), 15-25 (2019)

53. Kock, N.: Common method bias in PLS-SEM: A full collinearity assessment approach. Int. J. e-Collabor. (ijec) 11(4), 1-10 (2015)

54. Konradt, U., Warszta, T., Ellwart, T.: Fairness perceptions in web-based selection: Impact on applicants' pursuit intentions, recommendation intentions, and intentions to reapply. Int. J. Selec. Assess. 21(2), 155-169 (2013)

55. Kristof, A.L.: Person-organization fit: An integrative review of its conceptualizations, measurement, and implications. Pers. Psychol. 49(1), 1-49 (1996)

56. Langer, M., König, C.J., Krause, K.: Examining digital interviews for personnel selection: Applicant reactions and interviewer ratings. Int. J. Selec. Assess. 25(4), 371-382 (2017)

57. Lemmink, J., Schuijf, A., Streukens, S.: The role of corporate image and company employment image in explaining application intentions. J. Econ. Psychol. 24(1), 1-15 (2003)

58. Lev, B.: Intangibles: Management, Measurement, and Reporting. Brookings Institution Press. (2000).

59. Levin, K.A.: Study design III: Cross-sectional studies. Evid. Based Dent. 7(1), 24-25 (2006)

60. Liang, H., Saraf, N., Hu, Q., \& Xue, Y.: Assimilation of enterprise systems: the effect of institutional pressures and the mediating role of top management. MIS Quarterly, 59-87 (2007)

61. Logg, J.M., Minson, J.A., Moore, D.A.: Algorithm appreciation: People prefer algorithmic to human judgment. Organ. Behav. Hum. Decis. Process. 151, 90-103 (2019)

62. Mann, C.J.: Observational research methods Research design II: cohort, cross sectional, and case-control studies. Emerg. Med. J. 20(1), 54-60 (2003)

63. Marinchak, C.M., Forrest, E., Hoanca, B.: Artificial Intelligence: Redefining Marketing Management and the Customer Experience. Int. J. E-Entrep. Innov. (IJEEI) 8(2), 14-24 (2018)

64. Marler, J.H., Parry, E.: Human resource management, strategic involvement and e-HRM technology. Int. J. Hum. Resour. Manag. 27(19), 2233-2253 (2016)

65. Matthews, D. R., Son, J., \& Watchravesringkan, K.: An exploration of brand equity antecedents concerning brand loyalty: 
A cognitive, affective, and conative perspective. J. Bus. Retail Manag. Res. 9(1). (2014)

66. Meuter, M.L., Ostrom, A.L., Bitner, M.J., Roundtree, R.: The influence of technology anxiety on consumer use and experiences with self-service technologies. J. Bus. Res. 56(11), 899-906 (2003)

67. Mun, Y.Y., Hwang, Y.: Predicting the use of web-based information systems: self-efficacy, enjoyment, learning goal orientation, and the technology acceptance model. Int. J. Hum Comput Stud. 59(4), 431-449 (2003)

68. Nikolaou, I., Georgiou, K., Bauer, T., Truxillo, D.M.: Applicant Reactions in Employee Recruitment and Selection. In: Landers, R.N. (ed.) The Cambridge Handbook of Technology and Employee Behavior, pp. 100-130. Cambridge University Press, Cambridge, United Kingdom (2019)

69. Ocean, T. (2015). Annual Study of Intangible Asset Market Value from Ocean Tomo, https://www.oceantomo.com// intangible-asset-market-value-study/.

70. Oracle, The 2019 State of Artificial Intelligence in Talent Acquisition, https://www.oracle.com/a/ocom/docs/artificial-intelligen ce-in-talent-acquisition.pdf

71. Podsakoff, P.M., MacKenzie, S.B., Podsakoff, N.P.: Sources of method bias in social science research and recommendations on how to control it. Annu. Rev. Psychol. 63, 539-569 (2012)

72. Prahl, A., Van Swol, L.: Understanding algorithm aversion: When is advice from automation discounted? J. Forecast. 36(6), 691-702 (2017)

73. Pramod, D., Bharathi, S.V.: Social media impact on the recruitment and selection process in the information technology industry. Int. J. Hum. Cap. Inform. Technol. Prof. (IJHCITP) 7(2), 36-52 (2016)

74. Preacher, K.J., Hayes, A.F.: Asymptotic and resampling strategies for assessing and comparing indirect effects in multiple mediator models. Behav. Res. Methods 40(3), 879-891 (2008)

75. Pringle, R., Michael, K., Michael, M.G.: Unintended consequences of living with AI: The paradox of technological potential? Part II [Guest Editorial]. IEEE Technol. Soc. Mag. 35(4), 17-21 (2016)

76. Schijven, M., Nadolska, A., Boons, M., \& Barkema, H. G.: The Right People for the Job: Integrating Corporate Strategy, Top Team Composition, and Learning. In Academy of Management Proceedings (Vol. 2013, No. 1, p. 17630). Briarcliff Manor, NY 10510: Academy of Management (2013)

77. Ryan, R.M., Deci, E.L.: Intrinsic and extrinsic motivations: classic definitions and new directions. Contemp. Educ. Psychol. 25, 54-67 (2000)

78. Ryan, A.M., Horvath, M., Kriska, S.D.: The Role of Recruiting Source Informativeness and Organizational Perceptions in Decisions to Apply. Int. J. Selec. Assess. 13(4), 235-249 (2005)

79. Rynes, S.L., Bretz, R.D., Gerhart, B.: The importance of recruitment in job choice: a different way of looking. Pers. Psychol. 44(3), 487-521 (1991)

80. Schmitt, N., Gooding, R.Z., Noe, R.A., Kirsch, M.: Meta-analyses of validity studies published between 1964 and 1982 and the investigation of study characteristics. Pers. Psychol. 37, 407-422 (1984)

81. Sharma, A.: How AI reinvented hiring practice at L'Oréal. People Matters, 16 August (2018)

82. Smith, S.M., Roster, C.A., Golden, L.L., Albaum, G.S.: A multigroup analysis of online survey respondent data quality: Comparing a regular USA consumer panel to MTurk samples. J. Bus. Res. 69(8), 3139-3148 (2016)

83. Spector, P.E.: Do not cross me: Optimizing the use of crosssectional designs. J. Bus. Psychol. 34(2), 125-137 (2019)

84. Suen, H.-Y., Chen, M., Lu, S.H.: Does the use of synchrony and artificial intelligence in video interviews affect interview ratings and applicant attitudes? Comput. Hum. Behav. 98, 93-101 (2019)

85. Suen, H., Hung, K., Lin, C.: TensorFlow-Based Automatic Personality Recognition Used in Asynchronous Video Interviews. IEEE Access 7, 61018-61023 (2019)

86. Suen, H., Hung, K. \& Lin, C.: "Intelligent video interview agent used to predict communication skill and perceived personality traits." Human-centric Comput. Inform. Sci. 10, 3. (2020)

87. Sullivan, J.: Why you can't get a job... recruiting explained by the numbers. Electronic Recruiting, USA (2013)

88. Sylva, H., Mol, S.T.: E-Recruitment; A study into applicant perceptions of an online application system. Int. J. Selec. Assess. 17(3), 311-323 (2009)

89. Torkzadeh, G., Angulo, I.E.: The concept and correlates of computer anxiety. Behav. Inform. Technol. 11(2), 99-108 (1992)

90. Tyler, B.B., Kevin Steensma, H.: Evaluating technological collaborative opportunities: A cognitive modeling perspective. Strateg. Manag. J. 16(S1), 43-70 (1995)

91. Vallerand, R.J., Blssonnette, R.: Intrinsic, extrinsic, and amotivational styles as predictors of behavior: A prospective study. J. Pers. 60(3), 599-620 (1992)

92. Van Esch, P., Black, S.J.: Factors that influence new generation candidates to engage with and complete digital. AI-Enabled Recruit. Bus. Horizons 62(6), 729-739 (2019)

93. Van Esch, P., Black, J.S., Ferolie, J.: Marketing AI recruitment: The next phase in job application and selection. Comput. Hum. Behav. 90, 215-222 (2019)

94. Van Esch, P., Black, J. S., Franklin, D., \& Harder, M.: AI-enabled biometrics in recruiting: Insights from marketers for managers. Australasian Market. J. (AMJ) (2020)

95. Van Esch, P., Mente, M.: Marketing video-enabled social media as part of your e-recruitment strategy: Stop trying to be trendy. J. Retail. Consum. Serv. 44, 266-273 (2018)

96. Van Ingen, E., Bekkers, R.: Generalized trust through civic engagement? Evidence from five national panel studies. Polit. Psychol. 36(3), 277-294 (2015)

97. Venkatesh, V.: Determinants of perceived ease of use: Integrating control, intrinsic motivation, and emotion into the technology acceptance model. Inform. Syst. Res. 11(4), 342-365 (2000)

98. Viswesvaran, C.: Introduction to special issue: Role of technology in shaping the future of staffing and assessment. Int. J. Sel. Assess. 11(2-3), 107-111 (2003)

99. Webster, J., \& Martocchio, J. J.: Microcomputer playfulness: Development of a measure with workplace implications. MIS Quarterly, 201-226 (1992)

100. Wells, J.D., Campbell, D.E., Valacich, J.S., Featherman, M.: The Effect of perceived novelty on the adoption of information technology innovations: a risk/reward perspective. Dec. Sci. 41(4), 813-843 (2010)

101. Williamson, I., Lepak, D.P., King, J.: The effect of company recruitment web site orientation on indivi- duals' perceptions of organizational attractiveness. J. Vocat. Behav. 63, 242-263 (2003)

102. Winterich, K.P., Haws, K.L.: Helpful hopefulness: The effect of future positive emotions on consumption. J. Consum. Res. 38(3), 505-524 (2011)

103. Xu, Y., Shieh, C., Van Esch, P, \& Ling, I.: AI customer service: task complexity, problem-solving ability, and usage intention. Australasian Market. J. (2020)

104. Zhao, X., Lynch, J.G., Jr., Chen, Q.: Reconsidering baron and kenny: myths and truths about mediation analysis. J. Consum. Res. 37(2), 197-206 (2010)

105. Zusman, R.R., Landis, R.S.: Applicant preferences for web-based versus traditional job postings. Comput. Hum. Behav. 18(3), 285-296 (2002) 